\title{
THE FutURE OF ACCIDENT COMPENSATION: NEW DIRECTIONS AND VISIONS
}

\author{
Ruth Dyson*
}

These remarks were made by the Minister at the closing of the Symposium. They summarise much of the flavour of the discussion.

The theme of the Conference can be best summed up by saying that the future of our Accident Compensation Scheme is in restoring to it the vision, values and principles of the original Woodhouse Report of $1967 .^{1}$

That includes doing some things which we have never done before - such as having injury prevention as the primary focus of the Accident Compensation Corporation.

To most people in this room, the only criticism might be that this strategy has not gone far enough. Others will see this denial as a denial of their individual right to injure or kill themselves and others.

So to those who say we do not go far enough or fast enough - just remember that vision can only change reality if those who live in that reality change their actions. The key to change is education.

Restoring the scheme to the original vision of the Woodhouse Report will also mean ensuring that we are equitable in our responses to disabled people - regardless of the cause of impairment, be it illness or injury. You should have no doubts about my commitment to achieving this equity.

I have heard concern expressed about this in relation to the perceived cost to implement this strategy. People that raise this concern miss two points:

* Minister for ACC and Minister for Disability Issues.

1 New Zealand Royal Commission of Inquiry into Compensation for Personal Injury Compensation for Personal Injury in New Zealand: Report of the Royal Commission of Inquiry (Government Printer, Wellington 1967) [Woodhouse Report]. 
(1) Increased cost of a particular policy initiative does not determine whether this policy should be implemented - it merely determines the speed of its implementation.

(2) More importantly - and really at the heart of the Woodhouse Report - the cost of impairment is already in our society and is being borne by the individual. By not offering equitable support to a disabled person, we are adding to their individual cost and causing a loss of their contribution to society.

So, in basic economic terms, we are reducing our productivity by providing inequitable support and are thus imposing the total cost of impairment on an individual.

What I am proposing is to offer equitable support and recognise that the total cost should be properly borne by our whole society.

The next point I would like to make in relation to the future is that ACC needs to act and be seen to act as part of a "whole of government" approach. This is difficult for a Corporation as opposed to a government department, but it is possible. Throughout the discussions yesterday and today this has been very obvious.

The key to this approach (and in developing a comprehensive scheme) and a successful injury prevention strategy - remembering that the primary focus is injury prevention - is absolutely linked to health promotion.

Health promotion, and the ability to improve the health of people, is in turn linked to their socioeconomic status which is in turn linked to their education, and their education is linked to the reality of the "independence" of the ACC vocational independence process.

Seeing our Injury Prevention Strategy ${ }^{2}$ and our medical misadventure review ${ }^{3}$ as a critical part of public health improvement - not merely a programme to be implemented - and viewing our rehabilitation processes as a critical part of the Government's Growth and Innovation Strategy ${ }^{4}$ helps to promote a knowledge economy.

Two small policy ideas I have been looking at are capacity to earn rather than capacity to work, and of vocational independence being literally that - rather than the current situation.

The next point I want to make is that it has also been obvious that the quality of data that we have does not assist the high quality, robust debate that people in this room are keen to have. We

2 Hon R Dyson New Zealand Injury Prevention Strategy (Accident Compensation Corporation, Wellington, 2003).

3 Accident Compensation Corporation Review of ACC Medical Misadventure: Consultation Document (Accident Compensation Corporation, Wellington, 2003).

4 Office of the Prime Minister Growing an Innovative New Zealand (Government Printer, Wellington, 2002) 
need to improve that and it is high on my agenda. This need has been reinforced by this Conference.

Of interest to you might be the Government's agreement to move to outcomes measurement rather than outputs, which will make the previously mentioned issues very relevant.

Referring back to the original Woodhouse Report - there are two areas in which we have moved or will move away from. So, despite the iconic status that the Report enjoys (as Ken Oliphant noted yesterday ${ }^{5}$ ) there is not complete adoration for it. One area is the lump sum compensation issue and the other is the disentitlement for self-inflicted injury.

Other areas that may be changed that we have not yet considered include the levy structure and the account structure.

It is important that we have these and other debates in an open and considered way. Because the future of ACC will remain secure if it is seen to be fair, to deliver efficiently, and when proposed changes are understood and supported.

Your contribution to that has been and will continue to be very important.

Thank you for that and safe travel home!

5 Ken Oliphant "Beyond Woodhouse: Devising New Principles for Determining ACC Boundary Issues" (2004) 35 VUWLR 925. 
